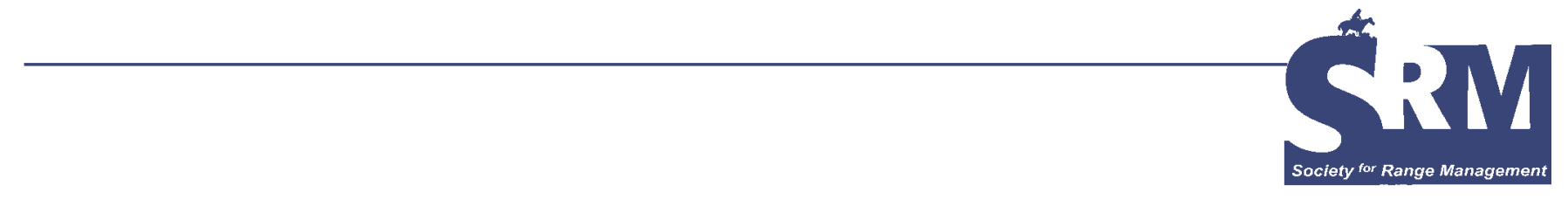

\title{
Resolving Critical Issues for the Development of Ecological Site Descriptions: Summary of a Symposium
}

\section{By Joel R. Brown and Brandon T. Bestelmeyer}

^ he concepts, methods, and procedures for describing rangelands help define the profession of range management. None of these is more important than the system for dividing rangelands into spatially distinct units for the purpose of classifying and managing. Range sites and range condition and the ecological concepts on which they were based dominated research, policy, and application virtually from the time SRM was formed (1948) until the late 1990s. In 1997, the revised version of the Natural Resources Conservation Service (NRCS) "National Range and Pasture Handbook" first referred to Ecological Site Descriptions (ESDs) and gave basic guidance on definitions and procedures for implementation. The change from range sites to ecological sites is representative of two important changes in the profession: the incorporation of nonequilibrium ecology to describe rangeland dynamics in some ecosystems, and the expansion of the array of ecosystem services provided by all rangelands.

In the $10 \mathrm{yr}$ since, ESDs have been developed and implemented across a wide variety of ecosystems using an array of assumptions and procedures. In 2005, the Bureau of Land Management (BLM), Forest Service (FS), and NRCS signed an interagency memorandum to collaborate and adopt ESDs as a standard for the description of rangelands. This multiagency agreement represents a substantial step forward in the application of a common terminology and an approach as a basis for land management decisions. However, this agreement represents primarily administrative progress. This administrative progress must be accompanied by scientific advancement. To review the progress to date, and to identify the impending challenges, we organized a symposium at the 2007 Annual SRM meeting in Reno,
Nevada. The speakers, their affiliations, and topics are listed in the sidebar.

Two important concepts emerged from the presentations and discussions. First, the ecological concepts and assumptions that underlie the development and implementation of ESDs are undergoing revision at a rapid pace. Most importantly, the assumption that reconstructing the ecological dynamics of a group of similar soil-vegetation occurrences as the basis for predicting future dynamics may be fatally flawed in light of a relatively rapid changing climate (Archer). As our understanding of both directional climate change and spatiotemporal variability (Bestelmeyer) improves,

\section{Speakers at the symposium and the topics} covered

Introduction-Brandon Bestelmeyer and Joel Brown The Ecology of Ecological Site Descriptions-Steve Archer, Professor, University of Arizona

Forest Overstory and Understory Characterization IssuesLyn Townsend, Forester, NRCS West National Technology Support Center, Portland, Oregon

How Important is Science to State and Transition Models and Ecological Site Descriptions?-Sam Fuhlendorf, Professor, Oklahoma State University

Improving Ecological Site Descriptions to Inform Land Management Policy-Joel Brown

Development of Ecological Site Descriptions at the State Level: Lessons Learned in California, Montana and Hawaii-Lori Metz, USDA NRCS, Hawaii State Office

Rethinking the Basis for Rangeland Management: The Mechanics of a Paradigm Shift from Range Sites to Ecological Site Descriptions-Jack Alexander, President, Synergy Resource Solutions, Bozeman, Montana 
our ability to predict ecological dynamics of specific soilvegetation combinations is undergoing a transformation. For example, changes in within-site spatial patterning of bare soil may be better indicators of impending state changes than traditional measures such as species composition.

In addition to relatively rapid changes in local and regional climates that may dramatically alter assumptions about the dynamics contained in ESDs, the presence of invasive species and their impact on ecosystem dynamics may have a profound influence on how we construct ESDs (Archer). The combination of invasive species (both native and exotic) will likely result in adventive, or novel, ecosystems adapted to the climatic and disturbance regimes currently in place, rather than those of the past. Because much of the predictive power of ecology is based on our understanding of the hierarchical nature of the relationships among genes, organisms, populations, and communities, and has been gained by observing historical changes, our assumptions will have to change to consider the impacts of new species and their interactions with other native and exotic species.

A continuing problem in ecology and ESDs is spatiotemporal scale. Several authors (Archer, Bestelmeyer, Fuhlendorf) explicitly referred to the need to clarify both the space and time aspects of ESDs. Although the spatial focus of ESDs (and the precursory Range Site Descriptions [RSDs]) has been the plant community, recent observation and experimentation have clearly identified spatial context as critical in explaining current conditions and predicting future changes. The interactions of individual plant communities with others in a landscape context may be just as important in predicting community dynamics as interactions of species within the community. Likewise, consistently describing the time scale in ecological dynamics has been an ongoing problem both in research and application. The importance of thresholds in defining both states and the transitions among states requires an explicit definition of the time frame of changes (Fuhlendorf, Bestelmeyer).

In addition to the biophysical nature of change and the assumptions associated with it, the uses and users of site descriptions are changing. The open-access delivery of ESDs over the Internet exposes this information to a whole new set of inquires and inquisitors. Likewise, as ESDs gain popularity across agencies and levels of government, the importance of consistency and transparency becomes paramount (Brown, Metz). Much of the information that has gone into the initial construction of ESDs is derived from RSDs and reflects the assumptions and objectives implicit in the assumptions associated with livestock grazing (Alexander). Both the assumptions about the biophysical drivers and outcomes of change, as well as the socioeconomic objectives inherent in site management, may no longer be valid or may be too limited to meet the variety of contemporary and future uses.
Development and application of ESDs have typically been a federal land management or technical assistance agency responsibility (largely NRCS, FS, or BLM rangeland specialists). As the list of users and uses expands, the potential for expanding involvement in the development and interpretation of ESD information also increases (Metz, Townsend). In addition to other natural resource-related disciplines (foresters, wildlife habitat specialists, hydrologists, etc.), other interest groups have valid interests in the development and use of ESDs. Conservation agencies and nonprofit organizations have both a vested interest in the use of ESDs for land they manage and valuable expertise for developing ESDs (Brown). Private consultants may be advising land managers or functioning as technical service providers for government agencies and will rely on the availability of accurate, consistent information contained in ESDs. In selected cases, private sector consultants may also perform some or all components of ESD development (Alexander, Metz). The end result is that the users and applications of ESDs are likely to expand far beyond their traditional uses of guiding decisions affecting commercial livestock production.

A second important point that emerged from the discussion was that all of the speakers placed an emphasis on the need to define core concepts of soil-vegetation patterning and organization prior to intensive site level data collection. That emphasis resulted both from an examination of the scientific and managerial bases of ESDs. The principles that govern ecological behavior of individual sites are not peculiar to any particular site, but may occur at global, continental, or regional scales and affect all sites, albeit to differing degrees (Archer). Investigating driving variables (i.e., climate, new, and novel species) and developing reliable predictions of their impacts will require a more systematic and organized examination of the relevant ecological processes and how they interact with existing and new management practices (Fuhlendorf), and how those interactions are affected by changes in spatial scale (Bestelmeyer). Accounting for the complexity in both time and space will preclude research scientists, projects, and programs from investigating individual site dynamics for every ecological site. The elucidation of the important aspects of site behavior that transcend individual sites and apply to multiple sites will require a concerted effort from research scientists, field technicians, and users in order to effectively design research and implementation initiatives (Brown).

Likewise, the need to build a system of ESDs that is easily accessible, credible, and transparent requires substantial effort to properly plan and implement. An ad hoc approach carried out state-by-state is unlikely to provide the necessary consistency for a broader array of applications. Speakers with extensive experience in ESD development (Metz, Townsend, Alexander) stressed the need for substantial up-front effort to define site concepts and thoughtful planning to test and refine those concepts as part of the 
ESD development process. The ecological criteria (processes, drivers) for grouping soils and for describing soil-vegetation dynamics must be clearly elucidated to provide testable hypotheses that will serve as a basis for both field data collection and research direction (Fuhlendorf, Archer, Bestelmeyer). The elucidation of site concepts and the design of field observations and experimental tests will provide a framework for the collaboration of field staff, users, and researchers. The interaction and collaboration were important points identified by all of the speakers in the symposium as both goals and the necessary first steps for success.

The effort of rangeland scientists and managers in implementing ESDs over the past decade has been gratifying and fruitful. The information generated and the lessons learned have both enlightened the process and created many challenges. As we enter the second decade in this effort to enhance and expand the scientific basis for rangeland management through ESDs, it is obvious that a more coordinated and systematic approach is necessary. Expanding the ecological and social basis for ESDs to include other types of land (forests, woodlands, shifting cultivation), other users (nature conservation, small landowners, low density development, policymakers) and other driving factors (climate change, invasive species, land use patterns) changes both the language and landscape. Providing a credible and transparent system with utility for all uses and users will require a more rigorous science and a more inclusive sociology.

The speakers and audience at the symposium identified some serious challenges that must be addressed if ESDs are to fulfill the substantial promise to rangeland management. At the same time, participants put forth some innovative responses to those challenges. From this exchange and others like it, it is obvious that the way ahead is unknown, but must be pursued by involving as many disciplines and people as possible.

Authors are Rangeland Scientist, Natural Resources Conservation Service, joelbrow@nmsu.edu (Brown); and Rangeland Ecologist, Agricultural Research Service, Jornada Experimental Range, PO Box 30003, New Mexico State University, Las Cruces, NM 88003-0003, USA (Bestelmeyer). 